\title{
LATINO STUDENT TRANSITION TO COLLEGE: Assessing Difficulties and Factors in Successful College Adjustment
}

\author{
Sylvia Hurtado, Deborah Faye Carter, and Albert Spuler
}

The primary purpose of this study is to understand the factors that affect Latino student adjustment in the first and second year of college. The study examines data from a national, longitudinal survey along with the Student Adaptation to College Questionnaire completed by Latino students judged to have high potential for success upon entering a variety of four-year colleges. Results show dimensions of the campus climate affect all forms of student adjustment, as do transitional experiences that are common to most students in the first year. Implications of the findings suggest further college programming and monitoring of adjustment in the second year of college.

Within the last decade, administrators developed programs directed at easing students' transition from high school to college as a means of reducing attrition rates in the first year. Specifically, there has been a recent proliferation of program activity and writing on the freshman-year experience (Upcraft, Gardner, and Associates, 1989; Shanely and Hearns, 1991) with increasing attention devoted to minority student transition to college (Ackerman, 1991; Graham, Baker, and Wapner, 1985). However, only a few studies have focused on the transition experiences of Latino ${ }^{1}$ college students or aspects of their adjustment (Attinasi, 1989; Ascher, 1985; Duran, 1983; Quintana, Vogel, and Ybarra, 1991; Smedley, Myers, and Harrell, 1993). Improved data collection methods, both at a national level and on individual campuses, reveal a portrait of Latino educational progress that is characterized by stagnation despite a growing, heterogeneous Latino population in the United States (Chapa and Valencia, 1993; Carter and Wilson, 1992). Given that this population has the potential for

An earlier version of this paper was presented at the Association of Institutional Research Forum in New Orleans, LA, May 1994. Sylvia Hurtado, Deborah Faye Carter, and Albert Spuler, University of Michigan, Center for the Study of Higher and Postsecondary Education. Address correspondence to Sylvia Hurtado, 610 University Avenue, 2117 School of Education Bldg., Ann Arbor, MI 48109-1259. 
growth in future enrollments at the postsecondary level (McCool, 1984), and as colleges continue to invest in attracting the most talented minority students to their campuses, research on Latino student transition to college life is both timely and necessary.

The primary purpose of this study is to understand the factors that affect the heterogeneous Latino student population and their adjustment to college life. Although the Latino students identified in this study have the highest potential for success, there is a significant amount of adjustment that must take place in the transition to any undergraduate institution. Our objective in this paper is to explore data from a national, longitudinal survey of Latino students and a psychometrically tested instrument in order to understand transitional experiences of the first year, perceptions and behaviors in the second year, and Latino student adjustment in the second year of college. As a guide to our analysis, we rely primarily on the developing body of literature that focuses on college adjustment as well as the literature on aspects of the minority experience that have been typically excluded from college impact models. Aspects of this experience include general campus and racial climate measures that have proven to be particularly important to minority students (Smedley et al., 1993; Hurtado, 1992; Quintana et al., 1991). Therefore, we set out to test results from previous college adjustment studies with a special focus on the minority experience.

The second year of college may be particularly important because it represents the time before a second transition occurs, in which students will soon make a commitment to an academic major and enter a new phase of their college career. According to researchers, the second year is a time when students become more dissatisfied with college and may experience a "sophomore slump" (Feldman and Newcomb, 1969). Additional evidence suggests that some institutions that recruit high-ability African American and Latino students have high first-year retention rates, but have increasing rates of attrition in subsequent years (Muñiz, 1994). Students may also experience additional difficulties, as one student wrote in our study, "Actually, my first year of college was rewarding and satisfying. ... [The] 2nd year is kicking my ass." Our goal is to provide researchers and practitioners with insights into aspects of the first year that may impact adjustment and Latino student success in the second and subsequent years of college.

\section{PERSPECTIVES ON COLLEGE ADJUSTMENT}

Research on student attrition addresses some aspect of college adjustment, either by implication or by including some measures that represent college adjustment directly in their models (Bennett and Okinaka, 1990; Chartrand, 1992). However, college adjustment has not typically been the object of systematic study, nor do researchers rely on a single definition of college adjust- 
ment that might distinguish it from other constructs used in attrition models (see Baker and Siryk, 1984, for a review). For example, Chartrand (1992) identifies the psychological outcomes in the Bean and Metzner Attrition Model (1985) as adjustment outcomes: Adjustment is defined as institutional commitment, feelings of academic adjustment, and the absence of psychological distress. Another study conceptualizes college adjustment as the "opposite of transitional trauma," which is defined as the "level of alienation a student experiences when unfamiliar with the norms, values, and expectations that predominate" (Bennett and Okinaka, 1990). Although linking college adjustment with attrition is of critical importance, a focus on the development and monitoring of college adjustment indicators is necessary if they are to serve as an effective early warning system for institutions (Krotseng, 1992). Moreover, without specific attention to the nature of transitional trauma, we are less informed about the difficulties students experience and the successful strategies that individuals and institutions use to resolve them.

One common element among studies that attempt to focus specifically on college adjustment is that they refer to some level of psychological distress (or lack thereof) and a variety of dimensions of a student's role that include personal, social, and academic arenas. Smedley, Myers, and Harrell (1993) use a stress-coping model to describe the adjustment process that occurs among minority freshmen. Using a variety of instruments, the authors measured chronic student role strain, episodic life events that cause stress, and minority status stressors in relation to three adjustment outcomes: psychological distress, feelings of well-being (e.g., health, mood, emotional stability), and academic achievement. They conceptualize college adjustment as a function of student attributes, psychological and sociocultural stresses, and the strategies students use to cope with these stresses. Their perspective is useful for the present study because they acknowledge that students face a variety of stressors in adjustment to any college, and that racial/ethnic minorities face additional stressors beyond those typical to all students. The authors found that interracial conflicts and experiences of overt discrimination were not as "debilitating minority status stressors as those that undermined students' academic confidence and ability to bond with the university. These stresses come from both internal sources as well as from demographic composition and social climate of the campus" (p. 448). While Smedley et al.'s approach is distinctly psychological in nature, our view builds on the sociological implications of their perspective. We focus on the environmental influences, which include the structural and climate characteristics of campuses that may facilitate or hinder areas of college adjustment.

A general assumption underlying many campus programs is that frequent interaction across race/ethnicity will lead to successful minority adjustment on predominantly white campuses. In a recent meta-analytic study of Latino student adjustment, Quintana, Vogel, and Ybarra (1991) concluded that "Latino 
students who are familiar and comfortable with Anglo culture experience less stress in universities that are dominated by Anglos" (p. 164). However, this view does not take into account the nature of the climate for intergroup relations. For example, sociologists posit that higher contact among different racial/ ethnic groups can sometimes result in increased opportunity for conflict (Blalock, 1967). Several studies have shown that Latino students tend to have more negative perceptions of the campus climate than white students (Hurtado, 1992; Loo and Rolison, 1986). In addition, Latino students are more likely to perceive racial/ethnic tensions in environments where they do not feel valued by the faculty and administration (Hurtado, 1994). Quintana et al. (1991) also found studies that show students' positive attitudes toward other groups and a secure ethnic identity were associated with lower levels of stress on campus. Therefore, different dimensions of a college's climate that include student interaction across race/ethnicity, perceptions of the climate for intergroup relations (racial/ethnic tension), experiences of overt discrimination, as well as the college's structural diversity in terms of Hispanic enrollments may affect Latino student adjustment.

There are additional characteristics of institutions that may impact college adjustment. College selectivity represents the general level of academic ability among the student body and, therefore, may pose challenges to academic adjustment for students. Both selective institutions and private institutions also tend to have distinct racial climates (Hurtado, 1992). College size may be particularly important in college adjustment because it may contribute to students' feelings of anonymity, sense of community, and isolation (Chickering and Reisser, 1993). However, students are often more satisfied with the diversity of opportunities for student life on large campuses (Astin, 1993). Still others contend that the impact of college size on college adjustment may have much to do with how students make sense of these environments, which is an important aspect of the early transition process (Attinasi, 1989). The significant contribution of each of these institutional characteristics to college adjustment, based on these research findings, was explored in this study.

Although researchers have used a variety of instruments to study college student adjustment in the past, we selected the Student Adaptation to College Questionnaire (SACQ) to assess adjustment to typical areas of student concern. Researchers have used the College Adjustment Questionnaire (Thompson and Fretz, 1991), the Student Transition Questionnaire (Chartrand, 1992), or the College Inventory of Academic Adjustment (Borow, 1949, cited in Baker and Siryk, 1984) to study student adjustment. We found that these instruments were either difficult to obtain, no longer in use, or are not widely used on college campuses. More importantly, developers of the SACQ have conceptualized college adjustment as a multifaceted construct whereby students may find ease in some areas and difficulty in other areas of college life (Baker and Siryk, 1989). 
Developers of the instrument also devote considerable attention to the publication and replication of research results, updating these periodically by contacting users of the SACQ instrument. For example, one study revealed that sophomores tend to score higher on the SACQ than first-year students, and that Hispanics tend to score lower on the SACQ than non-Hispanics (Albert, 1988, cited in Baker and Siryk, 1989). Thus, the SACQ instrument is accompanied by recent research results, norms for specific institutions, and helpful information about its use in college counseling. There are some aspects of the first-year transition experience, however, that are not currently measured by the SACQ instrument.

Researchers have begun to study a variety of postmatriculation experiences that provide insights into the difficulties and successful strategies individuals use in assuming their new college student roles. First, students must learn how to manage resources such as personal time and financial matters. Specifically, management of personal time is associated with anxiety among undergraduates (Strang, 1981). Financial concerns also create anxiety among students; several studies show that Latinos tend to experience greater levels of stress associated with financial concerns than Anglo students (Quintana et al., 1991). Another area of transition research involves students' separation from their families. Oncampus residents tend to be better adjusted to college than commuters (Wilson, Anderson, and Fleming, 1987), but one study qualifies these findings: it is not the actual distance from home that impacts adjustment but the perception of the distance being "just right" (Mooney, Sherman, and Lo Presto, 1991). This supports research that shows students are better adjusted when they maintain residential and economic independence, but also maintain a supportive relationship with parents (Anderson and Fleming, 1986).

Attinasi (1989) highlights a third area of student transition that involves making sense of large, new environments. Students resolve this transition dilemma by finding their niche and learning how to negotiate the physical, social, and cognitive geographies in college. These geographies are negotiated with the help of peer knowledge sharing and peer mentoring (p. 208), which is an important strategy for college adjustment. In summary, students' ease in managing resources, maintaining independence yet sustaining healthy family relationships/support, and success in getting to know their way around the various geographies of a campus are important transitional experiences in the first year that are hypothesized to have a positive effect on college adjustment in the second year.

\section{METHOD}

\section{Data Sources}

This study utilized five primary sources of data focusing on Latino college students who were among the top PSAT achievers identified as semifinalists for 
a national scholarship award (see Hurtado, 1994, for further details). Many of these students were highly sought after by colleges across the country, and as a result, had their choice of attending a wide variety of institutions. These national data constitute one of the few panel studies available on a select but important population of Latino students who demonstrate potential for academic success. Although the larger study focused on five cohorts of students, the current study focuses only on the cohort of Latino students who entered four-year colleges in 1991. Precollege information was obtained from the Student Descriptive Questionnaire, a survey administered to students when they took the SAT examination. The survey is designed to obtain information about a student's background, high school preparation, and college preferences. Analyses were limited to cases that had both SDQ data and responses to longitudinal follow-up surveys at two subsequent time points in their college career.

The National Survey of Hispanic Students (NSHS) was developed as a comprehensive longitudinal survey of college student experiences. The survey was sent to student home addresses in the late summer of 1991. A reminder postcard was sent two weeks after the first wave of surveys, and two weeks subsequent, a second survey was sent to nonrespondents' homes. Surveys arrived throughout early Fall of the 1991-1992 academic year, with an overall student response rate of 49 percent. In addition to the survey data, information about each college attended was linked with data from the U.S. Department of Education's Integrated Postsecondary Educational Data Systems (IPEDS), The College Handbook (1992), and institutional data files maintained by the Higher Education Research Institute at UCLA. For this study we relied primarily on the institutional enrollments and college selectivity data obtained from these sources.

A follow-up of the NSHS was sent to 487 students who were members of the 1991 cohort of entering freshman. Surveys were sent to parents' homes, college addresses when available, and updated addresses received the summer following administration of the first NSHS survey. Follow-up postcards were sent two weeks after the first wave, and a second survey was sent to nonrespondents four weeks later. Phone calls were made to nonrespondents with valid phone numbers obtained from the first survey. Finally, a third mailing of the survey was sent to nonrespondents in the summer. These efforts produced an overall response rate of 60 percent for the most recent survey.

The NSHS follow-up was developed specifically to compare student experiences and attitudes at the end of the second year of college with student responses on the first survey. The follow-up survey used new measures and replicated measures from other research studies, repeated questions from the first survey, and included newly developed measures. We conducted interviews with minority students, in their first and second year of college, in order to develop additional items regarding their transition experience. We developed a set of 
items that corresponded with their experience and modeled Attinasi's (1989) concepts of "getting in" and "getting to know" various campus geographies. Additional transition measures include survey items that reflected areas where students appeared to have the most difficulty during the freshman year (e.g., managing time, money, schedules, and issues regarding leaving home for college). See Table 1 for all variables, scales, and measures used in the model.

In addition to the NSHS follow-up, students in the 1991 cohort were sent the Student Adaptation to College Questionnaire (SACQ). The SACQ is a psychometrically tested instrument, used at many colleges and universities, that was designed to measure how well students adapt to the college experience (Baker and Siryk, 1989). The SACQ measures overall student adjustment and is composed of four main scales: Academic Adjustment, Social Adjustment, PersonalEmotional Adjustment, and Attachment. The SACQ's scales are described below as developed by Baker and Siryk $(1984,1989)$ :

1. Academic Adjustment: measures students' attitudes toward their academic work, the degree to which students feel motivated to do their work, and their satisfaction with their program.

2. Social Adjustment: measures students' involvement in social activities, success with interpersonal relationships, and satisfaction with their social environment.

3. Personal-Emotional Adjustment: measures the psychological health of students including how students respond to stress, and any physical manifestations of academic and social pressures.

4. Attachment: measures the degree to which students feel they belong in the institutional environment (e.g., I feel that I fit in well as part of . . environment) and students' institutional and goal commitments (e.g., I expect to stay at ... for a bachelor's degree).

With few exceptions (Graham, Baker, and Wapner, 1985), the SACQ has been used primarily in single-institution studies, and is often administered in classrooms along with other psychometric instruments. This study represents the first administration of the SACQ via mail to Latino students attending a variety of four-year institutions. There was a 51 percent response rate for the SACQ among the 1991 Latino cohort. While normally administered during the first six weeks of college to assess adjustment (Baker and Siryk, 1989), we administered the SACQ at a later time point to assess different aspects of the first year in relation to adjustment in the second year of college. Scales derived from the SACQ were constructed according to Baker and Siryk's (1989) instructions. Alpha reliabilities for each of the SACQ subscales, reported in Table 1, ranged from .86 to .88 and are similar to those specified in the literature (Baker and Siryk, 1989). This suggests that the SACQ scales are useful for 


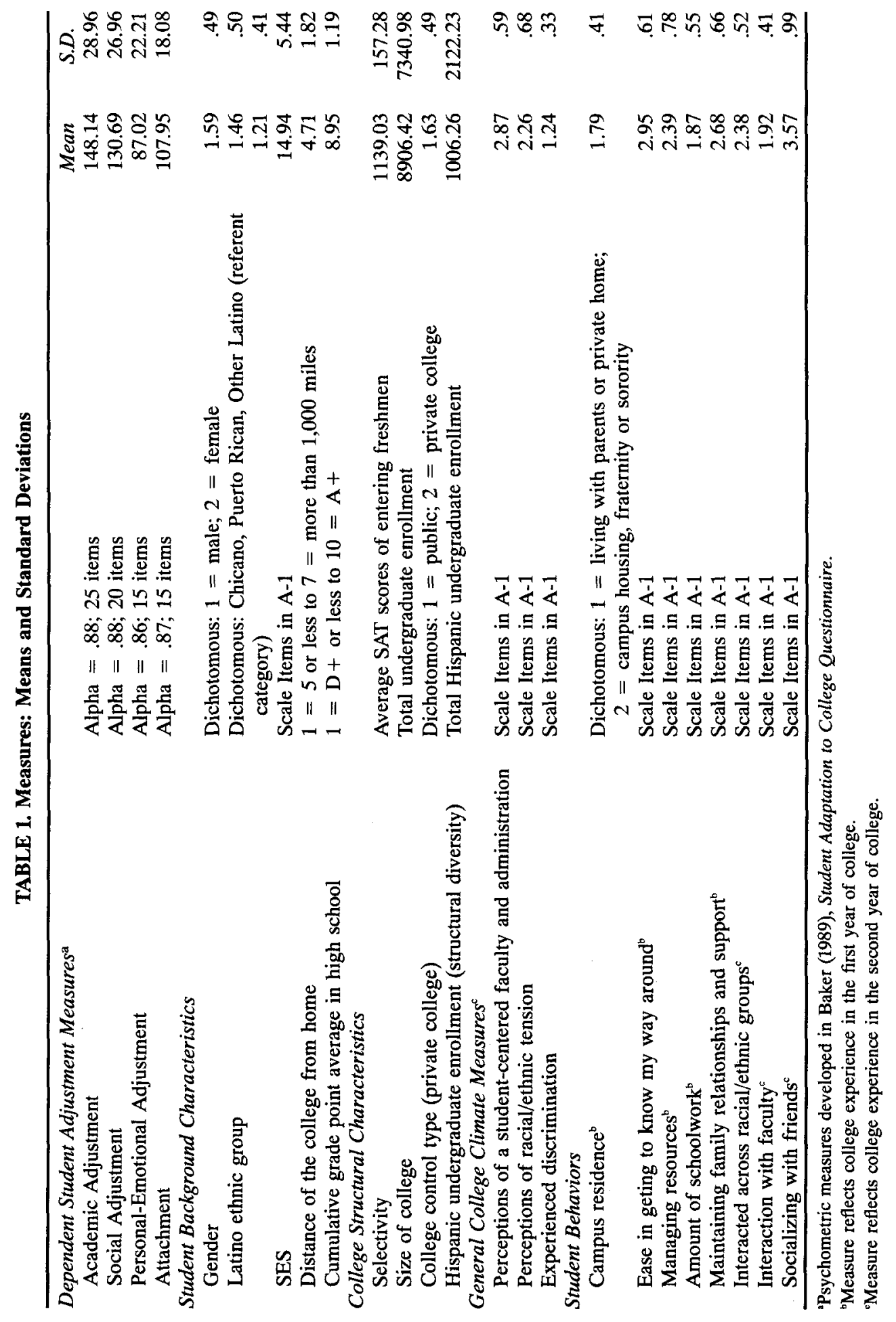


Latino students identified as high achievers in high school and also for the assessment of adjustment in the second year of college.

\section{Sample}

Analyses were limited to students who began college in the Fall of 1991 because we were interested in the adjustment of the most recent college entrants among the five NSHS cohorts. We also wished to combine the use of the SACQ instrument with information about their college experiences provided by the NSHS longitudinal data. Only those 203 students who had been matched with each of the other sources of data (SDQ, first NSHS survey, follow-up NSHS survey, institutional data, and SACQ) were selected for analysis. These data restrictions limited our sample to 42 percent of the initial group of students available for our study. Table 1 reveals descriptive information of our sample, based on means and standard deviations for all variables in the study. Females constitute 59 percent, Chicanos 46 percent, Puerto Ricans 21 percent, and Other Latinos (including Cubans, Central and South Americans) 33 percent of the sample. Students in our study, on the average, earned approximately an A average in high school and 63 percent of them attended private, four-year institutions. Although a high proportion were committed to attaining a baccalaureate upon college entry, we find considerable variation in the SACQ adjustment scores in the second year of college. This indicates that despite our best assumptions regarding student potential for success, one can find considerable variation in different dimensions of college adjustment among Latino students.

\section{Analyses}

Exploratory factor analyses were conducted, utilizing principal axis factoring and oblique rotation methods, to reduce the number of measured variables for analyses. Oblique factor analysis was favored in this study because we believe it is artificial to assume that these factors are uncorrelated. Oblique rotation also provides coefficient estimates that approximate coefficients obtained using advanced modeling techniques in additional studies of this cohort. Items that had a factor score of at least .35 or higher were retained in the development of subsequent scales. No item in our scales had a loading below .39, however. These results are available in Table A-1, along with alpha reliabilities. Multiple regression analyses were conducted to identify the significant determinants of each of the SACQ adjustment subscales. Independent variables that reflected student background characteristics, college structural characteristics, general college climate measures, and student behavior measures were entered in a hierarchical fashion. (See Table 1 for a listing of scales and measures used in the regression models.) This approach allowed the researchers to examine the 
relative contribution of three blocks of variables that included student background characteristics, structural characteristics, and finally, student perceptions of the climate and behaviors during college. It permitted us to examine whether the variation in college adjustment scales had less to do with preexisting student characteristics (ethnicity, sex, high school performance, income, etc.) than with the nature of the environments in which these students found themselves. After student background characteristics, structural characteristics were entered in the second block, as these college characteristics determine variation between colleges and exist independent of student and college experience measures. The final block of variables entered in the regression measured variation related to within-college environments, which included both student perceptions of the climate, transitional experiences, and other student behaviors in college.

In addition to the regression models, several analyses were conducted to assess student difficulties and facilitators of adjustment. We investigated the relationships between the SACQ adjustment scales and student reports of individuals/offices that assisted them in the first year of college. Partial correlations were conducted, controlling for student background characteristics, to assess the effects of categories of individuals that students identified as facilitating adjustment in college. Content analyses of open-ended questions were also conducted in order to obtain additional information about sources of support and difficulties in college. Categories were developed through an iterative coding process, where researchers coded the same responses, discussed discrepancies, and recoded student responses until consensus was developed about the category and the categorization of each student response.

\section{RESULTS}

Blocked hierarchical regression analyses revealed that, across all second-year adjustment outcomes, student background characteristics accounted for the lowest share of the explained variance when compared with the blocks for college structural and college experience measures in each equation. Student background characteristics contributed 9 percent of the variance ( $F$ change $p \leq .01$ ) in the Academic and Social Adjustment outcomes, and only 5 percent of the variance in the Attachment and Person-Emotional Adjustment equations. The block of institutional structural characteristics accounted for 8 percent, 7 percent, 8 percent $(F$ change $p \leq .001$ ), and 3 percent of the explained variance in Academic Adjustment, Social Adjustment, Attachment, and Person-Emotional Adjustment, respectively. The final block of measures that contained student perceptions of the college climate and student behaviors, including transition measures in the first year and student interactions measured in the second year of college, revealed a significant $F$ change of $p \leq .0001$ for all equations. These college experience measures alone accounted for approximately 28 per- 
cent of the total 45 percent of the variance explained for Academic Adjustment, 26 percent of the total 42 percent for Social Adjustment, 31 percent of the total 39 percent for Personal-Emotional Adjustment, and 23 percent of the total 37 percent of the variance in Attachment.

Table 2 shows the beta coefficients from regressing each of the SACQ adjustment measures (Academic, Social, Personal-Emotional, and Attachment) on all the independent measures. Controlling for all measures, results indicate that Chicanos were significantly less likely than other ethnic groups to score high on Social Adjustment in the second year of college. With this one exception, virtually none of the student background characteristics are significantly related to college adjustment. High school grade point average ${ }^{2}$ is not significantly related to academic adjustment in the second year of college. This indicates that differences between colleges and specific college experiences are more likely to directly affect college adjustment than any precollege measures for this specific student population.

College size has a significant effect on Social Adjustment and Attachment. However, inspection of the bivariate correlations show that size was not significantly related to these adjustment measures. Once other college experiences are controlled in the regression equations, such as the Ease in Getting to Know My Way Around scale in the Social Adjustment equation and attending a private college in the Attachment equation, we find that size is positively correlated with these two adjustment outcomes. This is called a suppressor effect, where the relationship between the two independent variables (e.g., size and private control of the college) hides or suppresses their real relationships with the dependent measures (Cohen and Cohen, 1983). Such a positive effect of size would not be evident in a single institution study or studies that neglect to control for a number of college type and measures of the transitional experience in a multivariate analysis. This finding indicates that students attending large institutions reported high social adjustment and attachment once the other measures were controlled in the study. The implications of this finding are detailed in the Discussion section of this paper.

Students who attended private colleges tended to score significantly higher on SACQ measures for social adjustment and attachment. In addition, students who attended institutions with higher Hispanic enrollments were more likely to report ease in academic adjustment in their second year of college. No other college structural characteristics had significant relationships with the adjustment measures.

Each of the college climate measures was significantly associated with different types of college adjustment. Latino perceptions of a student-centered faculty and administration were positively associated with scores on Academic Adjustment. In contrast, perceptions of a hostile climate for diversity were negatively associated with all adjustment measures. Specifically, perceptions of racial/eth- 


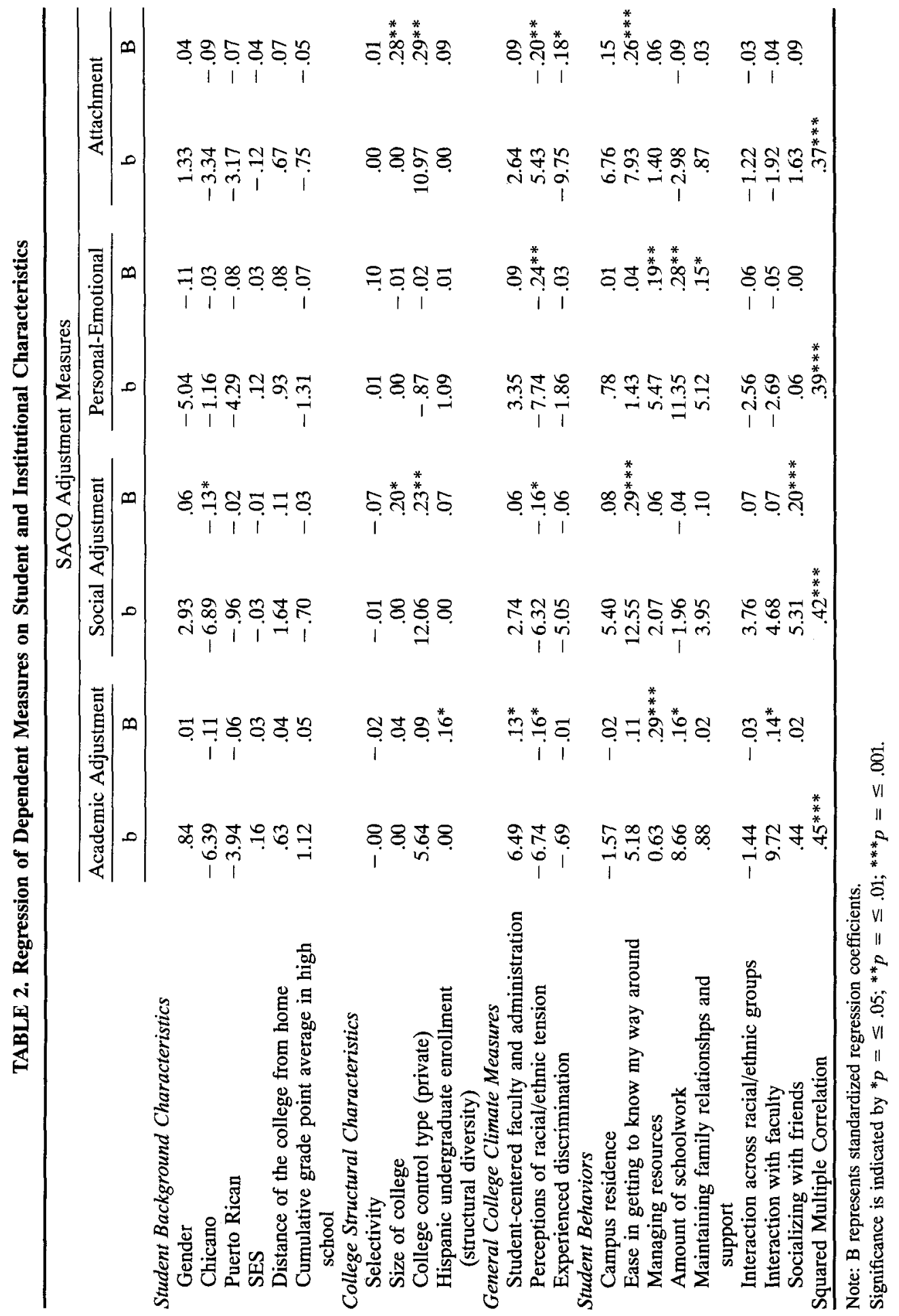


nic tension were negatively associated with Personal-Emotional, Academic, Social Adjustment, and Attachment scales. Students who actually reported experiences of discrimination also tended to score significantly lower on the Attachment scale.

Many student behaviors during the first and second year are positively associated with adjustment, suggesting that some of these experiences are important mediating experiences that facilitate successful adjustment to college. Managing such resources as time, money, and schedules and perceiving the amount of school work as manageable in the first year were positively associated with academic and personal-emotional adjustment in the second year. Interaction with faculty in the second year is also associated with academic adjustment, although the causal relationship between these measures is less clear because they were measured at the same time point. Maintaining family support in the first year was positively associated with personal-emotional adjustment. The Ease in Getting to Know My Way Around scale was positively related with the Social Adjustment and Attachment scales. The amount of time students spent socializing with friends in the first year was also positively associated with Social Adjustment. These results indicate important transitional experiences that affect adjustment in the second year of college.

In addition to those experiences that are important to adjustment, we examined information regarding assistance from individuals associated with the college. Students reviewed a list of resources that included university-related people and campus units and were asked to indicate those that "made it easier for you to adjust during your freshman year." Table 3 shows partial correlation results that reveal the relationship between the SACQ scales and resources (people/offices) that facilitated student adjustment in the first year. The partial correlations were conducted controlling for gender, ethnicity, SES, and high school GPA. Of the categories of individuals/offices listed, five had significant effects on student adjustment. Resident advisors, academic counselors, and upperclass students all had positive influence on student adjustment to the institution. Students who reported that resident advisors and upperclass students assisted in their first year scored higher on the Social Adjustment and Attachment scales in the second year of college. Resident advisors and other upperclass students can help students become familiar with social activities, the environment, and new relationships on campus. These individuals can help first-year students feel comfortable in their new environment.

There is a positive relationship between those students who felt their academic counselors helped them adjust and the Academic Adjustment and Attachment scales in the second year. However, students who felt that other freshmen assisted in their adjustment in the first year tended to be less well adjusted academically in the second year of college. This is preliminary evidence that suggests that students may need the guidance and support of upperclass students or peer mentors and staff members for successful academic adjustment. 
TABLE 3. Partial Correlation Coefficients: Individuals Who Helped Students Adjust During the First Year by SACQ Scales (Controlling for Gender, Ethnicity, SES, and High School GPA)

\begin{tabular}{lcccc}
\hline & Academic & Social & Personal/Emotional & Attachment \\
\cline { 2 - 5 } Resident Advisor & .02 & $.22^{* *}$ & -.05 & $.19^{* *}$ \\
Faculty Advisor & .08 & -.02 & .01 & .12 \\
Academic Counselor & $.19^{* *}$ & .12 & .08 & $.20^{* *}$ \\
Career Counselor & .05 & -.04 & .02 & .01 \\
Personal Counselor & -.10 & -.15 & -.06 & -.06 \\
Financial Aid Counselor & .09 & .05 & .02 & .08 \\
Peer Advisor & .10 & $-.14^{*}$ & -.04 & -.06 \\
Upperclass Students & .05 & $.20^{* *}$ & -.01 & $.19^{* *}$ \\
Other Freshman Students & $-.14^{* *}$ & .10 & -.05 & .05 \\
\hline
\end{tabular}

${ }^{*} p \leq .05 ;{ }^{* *} p \leq .01 ;{ }^{* *} p \leq .001$

Additionally, students who felt their peer advisors were most helpful in their first year scored lower on the Social Adjustment scale. This finding could be an artifact of the type of student who sought help and the kind of peer advisors they sought. Some students may face continuing social adjustment problems despite seeking help in the first year; in fact, these students may be more adjusted than they would have been if they had not sought help at all. Students may also not have sought the correct form of assistance, as the survey does not clarify the nature of these peer advisors. They are distinct, however, from resident assistants and other upperclass students who both have significant positive effects on adjustment. It is interesting to note that no single university-related resource we identified on our lists was significantly related to students' personal-emotional adjustment in the second year. This may be because we did not anticipate important support networks that contribute to adjustment in this area. Our qualitative analyses of open-ended questions revealed additional information about individuals (e.g., family members) that provided the most support for students in the first year, however.

\section{Open-Ended Responses}

Several open-ended questions were used in the NSHS follow-up in order to assess student perceptions of challenges, support, and climate issues in the transition process. Students listed up to four responses for each question, which were then coded, categorized, and frequencies were tabulated. This process was used for each case in the 1991 cohort and those results are reported here in their entirety. Student responses to the open-ended questions augment and confirm results obtained from statistical analyses.

In the first question, "What was the most difficult aspect of your first year?," 
we received an 89 percent response rate (Table 4) from survey respondents. Some of the most frequently cited responses revealed that academic adjustment (level of difficulty and amount of work) during the first year was the most difficult, representing 31 percent of the responses. Students indicated that most difficulties were due to new performance standards: "Not getting the grades I was used to. I was never at the bottom of a bell curve before." Many students felt the pressures of no longer being at the top of the class. One student recalled experiencing difficulties in "Getting adjusted to no longer being the brightest student (or one of) in the school."

Maintaining and establishing social relationships such as those between college peers, family, and friends was also a common difficulty, representing 22 percent of the responses. Many students cited "homesickness," "separation from family and friends," and "being accepted" by campus peers as common difficulties. Some felt the most difficulty in "Getting a support system together. When I got stressed out I didn't want to go crying and complaining to my new friends or home to my family. Now I do though."

The third most frequently described difficulty for these students was managing time, which represented 20 percent of responses. It became evident that students in the second year continue to struggle with time management concerns. Students expressed difficulties in "Learning to manage my time to do all my work and still be involved. I still have trouble"; "Learning to manage time effectively [was the most difficult aspect of my first year]. There are a lot of distractions at school."

Several students also cited the climate for diversity, ethnic/cultural adjustment, and recognition of inequality as a difficulty in their first year. The most difficult transition issues for some students entailed "[The] social aspect-[the] attitude of students here was much colder and less caring than in my own violent neighborhood"; "Realizing that my life would be a struggle because of the way the system is biased against my ethnicity"; "Being treated as inferior by people who only knew that I was a Hispanic (like they didn't know that I did have a brain, and some morals, and a good upbringing)."

In order to understand individuals who were influential in helping students through these difficulties, another question was posed: "Who provided the most support for you during your freshman year?" (Table 5). The student response rate for this question was 95 percent. The majority of responses ( 38 percent) revealed that students felt college peers including upperclass students, other freshmen, roommates, boyfriends/girlfriends, and residence hall staff provided the most support: "The upperclass Latino students took me under their wing academically and socially"; "[The most support came from] fellow students and knowing that other students had the same troubles and concerns I had. We students would talk to each other about school, family, problems, etc., offering each other support and friendship."

Another strong area of support for students during their transition from high 
TABLE 4. Student Response Summary: The Most Difficult Aspects of the First Year

\begin{tabular}{lrc}
\hline Response rate to item: $89 \%$ & $N$ & Percentage \\
\hline Academic Adjustment & 105 & 29.3 \\
Social Relationships & 77 & 21.5 \\
Time Management & 59 & 16.5 \\
General Adjustment to Environment & 43 & 12.0 \\
Financial Aid/Money/Working & 22 & 6.1 \\
Ethnic/Cultural Adjustment & 14 & 3.9 \\
Outsider (being alone, not being accepted) & 12 & 3.4 \\
Transportation & 10 & 2.8 \\
Geographic Adjustment & 8 & 2.2 \\
Health & 4 & 1.1 \\
No Difficulties & 3 & .8 \\
Historical Events & 1 & .3 \\
\hline
\end{tabular}

Note: Up to four multiple responses to the question were tabulated for each case $(N=358$ responses).

school was their family ( 28 percent of all responses). Students indicated: "My mother, father, and brother [provided the most support]. They stood behind me in all that I did and helped when they could"; "My family [provided the most support]. My grades were there, but my family knew I was homesick and did everything they could to assure me that it was a worthwhile sacrifice."

The third most frequently cited source of support was friends (unspecified), representing 15 percent of all responses. Students commonly cited "friends I made at school," "friends from home," "friends that I made in the dorm," or simply stated that "friends" provided the most support in their transition to college.

TABLE 5. Student Response Summary: Individuals Who Provided the Most Support During the First Year

\begin{tabular}{lrc}
\hline Response rate to item: 95\% & $N$ & Percentage \\
\hline College Peers (boy-/girlfriend, roommates, other students) & 151 & 38.2 \\
Family & 109 & 27.6 \\
Friends (nonspecific) & 61 & 15.4 \\
Administration and Faculty & 42 & 10.6 \\
Myself & 13 & 3.3 \\
High School Friends, Teachers, Counselors (outside college) & 11 & 2.8 \\
Other & 8 & 2.0 \\
\hline
\end{tabular}

Note: Up to four multiple responses to the question were tabulated for each case $(N=395$ responses). 
The responses offered by students in the open-ended questions added to our knowledge base concerning challenges that students faced, people and offices on campus that provided the most support, and student perceptions of campus climate. These results point to issues on campus and factors off campus that are influential in providing support and assisting the transition process in the first year. The support of family is clearly key for the transition process and is a factor that was not especially anticipated when initially conceptualizing the survey. The complexity of difficulties and student strategies for success is difficult to conceptualize from our standpoint as college researchers, which necessitates the collection and combined reporting of qualitative and quantitative information obtained from students.

\section{DISCUSSION}

This study provides insights into the transition experiences and the adjustment of Latino students in the second year of college. Based on prior research, college adjustment was conceptualized in this study as a multifaceted phenomenon that is characterized by the resolution of psychological distress or transitional trauma. We assessed individual attributes, college structural and climate characteristics, student transitional experiences, and student behaviors in order to understand both the difficulties and facilitators of college adjustment in four areas: academic, social, personal-emotional, and attachment to the institution. The Student Adaptation to College Questionnaire proved to be a reliable indicator of adjustment for this population and was especially useful in combination with longitudinal survey data that examined specific dimensions of the Latino college experience. These instruments provided information about typical adjustment concerns common to most college students, as well as issues that may pose particular problems for minority students on predominantly white campuses. Using previous college adjustment research and analysis of data in the current study, we have identified some generalizable patterns in the college adjustment process that have important implications for institutional policy.

We found confirmation for Smedley et al.'s (1993) findings that revealed a significant contribution of climate-related minority status stressors, over and above some of the typical transitional difficulties. Experiences of discrimination have a depressing effect on Latino students' feelings of attachment to the institution; however, it was the perception of racial/ethnic tension that was directly associated with lower levels of personal-emotional adjustment, attachment to the institution, and (to a lesser extent) adjustment in the academic and social arenas. Thus, it is not just the overt experiences of discrimination that require our attention, but rather attention to the more subtle forms of intergroup dynamics that can undermine all forms of college adjustment for Latino students. The measure of racial/ethnic tension in this study captures subtle intergroup dynamics on campus. Even the most talented Latinos are likely to have diffi- 
culty adjusting if they perceive a climate where majority students think all minorities are special admits, Hispanics feel like they do not "fit in," groups lack good communication, there is group conflict, and there is a lack of trust between minority students and the administration. Students may internalize these climate observations, presumably because these are more difficult to identify or sanction than overt forms of discrimination. One way to improve racial climate perceptions is to develop programs that seek to change intergroup dynamics by providing opportunities for students from different racial/ethnic backgrounds to discuss their perceptions, misconceptions, and achieve a better understanding of each other through intergroup dialogue (Zúniga and Nagda, 1993).

Developing programs for increased communication between student groups provides a more thoughtful solution than simply requiring Latinos to "integrate" themselves among majority students. While a small proportion (4 percent) of student responses highlighted difficulty in the areas of ethnic/cultural adjustment, there is no clear evidence in this study to support the idea that increased "racial/ethnic mixing" will result in acculturation and consequently successful college adjustment among Latinos. Latino students who interacted frequently with other racial/ethnic groups were not significantly more likely to demonstrate higher levels of college adjustment. However, we do need additional information about variations in college adjustment that may be related to cultural differences among Latino ethnic groups. We recommend further research on the unique experiences of Chicano students, for example, who tend to demonstrate lower levels of social adjustment in comparison to other Latino groups in this study.

Aside from these specific aspects of the minority experience on campus, we found that aspects of the general transition experience were key to college adjustment in subsequent years. Successful management of student resources (time, schedules, and finances) in the first year has a strong impact on academic and personal-emotional adjustment in the second year of college. Latinos who experienced less difficulty in the first year with the level and amount of school work also demonstrated high levels of personal-emotional adjustment and academic adjustment in the second year. Students who successfully negotiated the physical, social, and cognitive geographies on campus (on the Ease in Getting to Know My Way Around scale) had significantly higher social adjustment and attachment to the institution. It should also be noted that the positive effect of college size on adjustment was contingent upon the successful negotiation of these campus geographies (evidenced by the suppressor effects in the regression equation). This supports the idea proposed by Attinasi (1989) that suggests students make sense of large environments by locating themselves within more manageable campus geographies. These findings emphasize the need to direct further college programs toward monitoring of student resource management, academic workloads, and assisting students in becoming familiar with the campus environment. 
One of the clear facilitators of student adjustment involves the nature of affiliations that students develop with peers (both within ethnic groups and across ethnic groups). The results revealed how important upperclass students are to a student's adjustment to the campus community. Upperclass students and resident advisors significantly influence students' social adjustment and attachment. These findings reinforce the importance of peer knowledge sharing and peer mentors (Attinasi, 1989). However, we found some evidence that suggests students who rely solely on their freshman peers for support in the area of academic adjustment may be ultimately disadvantaged. Exclusive associations with other first-year students may provide some level of support but these do not provide the support students need to make positive changes in their academic habits. Students indicated that academic counselors were particularly important in facilitating their academic adjustment and attachment to the institution.

Student responses on open-ended questions revealed that in addition to the help of peers, the support of their family was an important aspect of college adjustment in the first year. Quantitative results confirm better personal-emotional adjustment among students who had less difficulty separating from the family while also maintaining family relationships and support. This research indicates that students may be better adjusted when they maintain independence, but also maintain a supportive relationship with parents (Anderson and Fleming, 1986). This may be one reason why the distance from home and residing on campus were not significant indicators of adjustment. Maintaining quality student-parent relationships as well as adequate personal autonomy are more influential in the transition process.

Academic adjustment to college in the second year was not significantly related to any of the precollege indicators, presumably because many of the key experiences that occur in the first year have more of an impact on subsequent years in college. For example, becoming accustomed in the first year to the amount and level of school work, managing resources (time, schedules, and finances), and the structural diversity of the institution are more important to academic adjustment. Latinos who attend colleges where they perceive a student-centered faculty and administration and have opportunities for interaction with faculty are more likely to be academically adjusted in the second year. High school grade point average is not directly related to academic adjustment for this Latino sample. Thompson and Fretz (1991) also found that standardized high school grade point averages were not significantly related to academic or social adjustment for African American freshmen. This suggests that academic adjustment for minority students is not directly related to prior high school performance, yet we leave open the possibility for testing indirect relationships in the future.

It appears that students' in-college experiences affect their adjustment far more than student background characteristics. Given this finding, there is some merit to monitoring the college adjustment process in a variety of student life 
domains through counseling, dormitory programming, or the use of psychometric instruments. Monitoring adjustment is a useful strategy for administrators, institutional researchers, and faculty who wish to improve their student retention rates. For institutions with high first-year retention rates, or who recruit high-ability students, we suggest the development of programs directed at improving second-year college experiences in addition to extensive freshmanyear programming. Second-year students are about to undergo a second transition in preparation for the major, and negative campus experiences and unresolved difficulties will only create additional trauma. Those who wish to improve college adjustment, however, must also look beyond individual factors to consider aspects of the campus climate that may need improvement for the success and valuing of all students.

Acknowledgments. We thank Beverly Dale and Angela Pipkin for their work on this project.

\section{NOTES}

1. We use the term Latino as a general term to refer to Mexican American, Puerto Rican, Cuban, Central and South American, and Spanish Carribean students.

2. Additional regression analyses were conducted using SAT scores to examine the relationship between prior performance and the SACQ scales. Results confirmed that neither high school GPA nor SAT scores were significant predictors of academic adjustment in the second year. The SAT scores were normally distributed, ruling out the possibility of a restricted range problem.

\section{REFERENCES}

Ackerman, S. P. (1991). The benefits of summer bridge programs for underrepresented and low-income students. College and University 66(4): 201-208.

Anderson, S. A., and Fleming, W. M. (1986). Late adolescents' home-leaving strategies: Predicting ego identity and college adjustment. Adolescence 66: 453-459.

Ascher, C. (1985). Helping Hispanic students to complete high school and enter college. Urban Review 17(1): 65-72.

Astin, A. W. (1993). What Matters in College: Four Critical Years Revisited. San Francisco: Jossey-Bass.

Attinasi, L. C., Jr. (1989). Getting in: Mexican Americans' perceptions of university attendance and the implications for freshman year persistence. Journal of Higher Education 60(3): 247-277.

Baker, R. W., and Siryk, B. (1984). Measuring adjustment to college. Journal of Counseling Psychology 31(2): 179-189.

Baker, R. W., and Siryk, B. (1989). Student Adaptation to College Questionnaire Manual. Los Angeles: Western Psychological Services.

Bean, J. P., and Metzner, B. S. (1985). A conceptual model of nontraditional undergraduate student attrition. Review of Educational Research 55: 485-539. 
Bennett, C., and Okinaka, A. M. (1990). Factors related to persistence among Asian, black, Hispanic, and white undergraduates at a predominantly white university: Comparison between first and fourth year cohorts. Urban Review 22(1): 33-60.

Blalock, H. M. (1967). Toward a Theory of Minority-Group Relations. New York: Wiley. Carter, D. J., and Wilson, R. (1992). Minorities in Higher Education: Tenth Annual Status Report. Washington, DC: American Council on Education.

Chapa, J., and Valencia, R. R. (1993). Latino population growth, demographic characteristics, and education stagnation: An examination of recent trends. Hispanic Journal of Behavioral Sciences 15(2): 165-187.

Chartrand, J. M. (1992). An empirical test of a model of nontraditional student adjustment. Journal of Counseling Psychology 39(2): 193-202.

Chickering, A.W., and Reisser, L. (1993). Education and Identity. San Francisco: JosseyBass.

Cohen, J., and Cohen, P. (1983). Applied Multiple Regression/Correlation Analysis for the Behavioral Sciences, 2nd ed. Hillsdale, NJ: Lawrence Erlbaum Associates.

College Entrance Examination Board (1991). The College Handbook, 1992. New York: College Entrance Examination Board.

Duran, R. P. (1983). Hispanics' Education and Background: Predictors of College Achievement. New York: College Board Publications.

Feldman, K., and Newcomb, T. (1969). The Impact of College on Students. San Francisco: Jossey-Bass.

Graham, C., Baker, R. W., and Wapner, S. (1985). Prior interracial experience and black student transition into predominantly white colleges. Journal of Personality and Social Psychology 47(5): 1146-1154.

Hurtado, S. (1992). The campus racial climate: Contexts for conflict. Journal of Higher Education 63(5): 539-569.

Hurtado, S. (1994). The institutional climate for talented Latino students. Research in Higher Education 35(3): 21-41.

Krotseng, M. V. (1992). Predicting persistence from the Student Adaptation to College Questionnaire: Early warning or siren song? Research in Higher Education 3(1): 99-111.

Loo, C. M., and Rolison, G. (1986). Alienation of ethnic minority students at a predominately white university. Journal Higher Education 57(1): 58-77.

McCool, A. C. (1984). Improving the admission and retention of Hispanic students-A dilemma for higher education. College Student Journal, 18: 28-36.

Mooney, S. P., Sherman, M. F., and Lo Presto C. T. (1991). Academic locus of control, self-esteem, and perceived distance from home as predictors of college adjustment. Journal of Counseling and Development 69(3): 445-448.

Muñiz, D. (1994). Factors that predict Hispanic persistence in a predominantly white institution: A comparison with African American students. Unpublished doctoral dissertation, University of Michigan, Ann Arbor, MI.

Quintana, S. M., Vogel, M. C., and Ybarra, V. C. (1991). Meta-analysis of Latino students' adjustment in higher education. Hispanic Journal of Behavioral Science 13(2): $155-168$.

Shanely, M., and Hearns, R. (1991). The freshman year experience in American higher education: An annotated bibliography. Suggested readings and resources for higher education faculty and administrators involved in promoting student success during the freshman year and beyond. The Freshman Year Experience, Monograph Series No. 3. Columbia, SC: Center for the Study of the Freshman Year Experience.

Smedley, B. D., Myers, H. F., and Harrell, S. P. (1993). Minority-status stresses and the college adjustment of ethnic minority freshmen. Journal of Higher Education 64(4): 434-452. 
Strang, H. R. (1981). Time management anxiety in undergraduate students. College Student Journal 15(4): 365-369.

Thompson, C. E., and Fretz, B. R. (1991). Predicting the adjustment of black students at predominantly white institutions. Journal of Higher Education 62(4): 437-450.

Upcraft, M. L., Gardner, J. N., and Associates (1989). The Freshman Year Experience: Helping Students Survive and Succeed in College. San Franciso: Jossey-Bass.

Wilson, R. J., Anderson, S. A., and Fleming, W. M. (1987). Commuter and resident students' personal and family adjustment. Journal of College Student Personnel 28(3): 229-233.

Zúñiga, X., and Nagda, B. A. (1993). Dialogue groups: An innovative approach to multicultural learning. In D. Schoem, L. Frankel, X. Zúñiga, and E.A. Lewis (eds.), Multicultural Teaching in the University (pp. 313-333). Westport, CT: Praeger.

Received September 28, 1994.

TABLE A-1. Factors Used in Analyses

\begin{tabular}{|c|c|c|}
\hline Factors and Survey Items & $\begin{array}{l}\text { Factor } \\
\text { Loading }\end{array}$ & $\begin{array}{l}\text { Internal } \\
\text { Consistency } \\
\text { (Alpha) }\end{array}$ \\
\hline $\begin{array}{l}\text { Socioeconomic Status (First Year) } \\
\text { Parental income } \\
\text { Level of mother's education } \\
\text { Level of father's education }\end{array}$ & & .78 \\
\hline Managing Resources (First Year) & & .77 \\
\hline Staying on a schedule ${ }^{d}$ & .91 & \\
\hline Managing my time effectively ${ }^{\mathrm{d}}$ & .84 & \\
\hline Managing my money effectively & .49 & \\
\hline Ease in Getting to Know My Way Around (First Year) & & .66 \\
\hline Seeking help when I need it ${ }^{d}$ & .84 & \\
\hline Getting to know my way around ${ }^{d}$ & .54 & \\
\hline Communicating with instructors $^{d}$ & .53 & \\
\hline Making new friends ${ }^{d}$ & .39 & \\
\hline Amount of Schoolwork (First Year) & & .72 \\
\hline Ease of level of difficulty of schoolwork & .83 & \\
\hline Amount of schoolwork ${ }^{b}$ & .79 & \\
\hline $\begin{array}{l}\text { Felt overwhelmed by all I had to do (Reversed for } \\
\text { analyses) }\end{array}$ & -.43 & \\
\hline Maintaining Family Relationships and Support (First Year) & & .65 \\
\hline Being separated from family & .62 & \\
\hline Felt lonely or homesick (Reversed for analyses) ${ }^{\text {c.f }}$ & -.71 & \\
\hline Maintaining family relationships ${ }^{\mathrm{d}}$ & .45 & \\
\hline Student-Centered Faculty and Administration (Second Year) & & .79 \\
\hline $\begin{array}{l}\text { Faculty here are strongly interested in the academic } \\
\text { problems of undergraduates }{ }^{b}\end{array}$ & .74 & \\
\hline Faculty here are interested in students' personal problems ${ }^{b}$ & .67 & \\
\hline
\end{tabular}


TABLE A-1. Continued

\begin{tabular}{|c|c|c|}
\hline Factors and Survey Items & $\begin{array}{l}\text { Factor } \\
\text { Loading }\end{array}$ & $\begin{array}{c}\text { Internal } \\
\text { Consistency } \\
\text { (Alpha) }\end{array}$ \\
\hline $\begin{array}{l}\text { Campus administrators care little about what happens to } \\
\text { students (Reversed for analyses) }\end{array}$ & -.62 & \\
\hline $\begin{array}{l}\text { Administrators consider student concerns when making } \\
\text { policy }^{b}\end{array}$ & .57 & \\
\hline Faculty are committed to the welfare of this institution ${ }^{b}$ & .55 & \\
\hline Perceptions of Racial/Ethnic Tension (Second Year) & & .80 \\
\hline $\begin{array}{l}\text { Most students at this institution believe that minorities } \\
\text { were special admits }\end{array}$ & .68 & \\
\hline $\begin{array}{l}\text { Many Hispanic students feel like they do not "fit in" on } \\
\text { this campus }\end{array}$ & .68 & \\
\hline $\begin{array}{l}\text { Students of different racial/ethnic origins communicate } \\
\text { well with one another (Reversed for analyses) }\end{array}$ & -.68 & \\
\hline There is a lot of campus racial conflict here ${ }^{b}$ & .67 & \\
\hline $\begin{array}{l}\text { There is little trust between minority student groups and } \\
\text { campus administrators }{ }^{\mathrm{b}}\end{array}$ & .59 & \\
\hline Experienced Discrimination/Exclusion (Second Year) & & .61 \\
\hline $\begin{array}{l}\text { Felt excluded from school activities because of your } \\
\text { Hispanic background }\end{array}$ & .64 & \\
\hline $\begin{array}{l}\text { Were insulted or threatened by other students because of } \\
\text { your Hispanic background }{ }^{c}\end{array}$ & .63 & \\
\hline $\begin{array}{l}\text { Heard faculty make inappropriate remarks regarding } \\
\text { minorities }\end{array}$ & .48 & \\
\hline Felt pressure to socialize only with other Hispanic students ${ }^{\mathrm{c}}$ & .42 & \\
\hline Interacted Across Racial/Ethnic Groups (Second Year) & & .71 \\
\hline Dined with someone from a different racial/ethnic group ${ }^{c}$ & .76 & \\
\hline Studied with someone from a different racial/ethnic group ${ }^{c}$ & .64 & \\
\hline Had a roommate from a different racial/ethnic group & .51 & \\
\hline Dated someone from a different racial/ethnic group ${ }^{c}$ & .43 & \\
\hline Interaction with Faculty (Second Year) & & .62 \\
\hline Talked with faculty outside of class ${ }^{c}$ & .81 & \\
\hline Time spent talking with teachers outside of class ${ }^{e}$ & .49 & \\
\hline Been a guest in a professor's home ${ }^{\mathrm{c}}$ & .46 & \\
\hline Had a class paper critiqued by an instructor ${ }^{c}$ & .39 & \\
\hline Socializing with Friends (Second Year) & & .59 \\
\hline Time spent partyinge & .70 & \\
\hline Time spent socializing with friends ${ }^{e}$ & .56 & \\
\hline
\end{tabular}

"Factor developed in Hurtado (1994).

"Four-point scale: From "Disagree strongly" $=1$ to "Agree strongly" $=4$.

Three-point scale: From "Not at all" $=1$ to "Frequently" $=3$.

"Four-point scale: From "Very difficult" $=1$ to "Very easy" $=4$

"Six-point scale: From "none" $=1$ to " $20+$ hours" $=6$

'Oblique rotation reverses the sign of the factor in the estimation process. As the factor name implies, all were positively scaled for subsequent analyses. 